\title{
Assessment of quality of life and psychosocial status of mothers whose children underwent congenital heart surgery
}

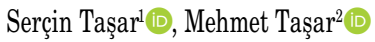 \\ ${ }^{1}$ Department of Pediatrics, Ankara Training and Research Hospital, Ankara, Turkey \\ ${ }^{2}$ Department of Pediatric Cardiovascular Surgery, Dr. Sami Ulus Maternity, Child Health Training and Research Hospital, Ankara, Turkey \\ Received: June 23, 2021 Accepted: July 08, 2021 Published online: August 11, 2021
}

\begin{abstract}
Objectives: The aim of this study was to assess the quality of life of mothers whose children underwent cardiac surgery.

Patients and methods: This prospective, case-control study included a total of 103 children (52 males, 51 females; mean age: $59.1 \pm 56.1$ months; range, 1 month-18 years) who underwent congenital heart surgery and their mothers between September 2019 and April 2020. The children who underwent cardiac surgery and their mothers were included as the study group ( $\mathrm{n}=48$ ). The control group ( $\mathrm{n}=55$ ) included healthy children and their mothers. Sociodemographic data of the children and their mothers were recorded. The World Health Organization Quality of Life-BREF (WHOQOL-BREF) questionnaire was administered to the mothers.

Results: Both groups were similar in terms of age, sex, height, and birth weight, maternal age, education and marital status, and presence of comorbidities $(\mathrm{p}>0.05)$. The scores in a 0-100 scale of physical health, psychological health, social relationships and environment domains of the WHOQOL-BREF were statistically lower in the study group $(\mathrm{p}<0.05)$. Intensive care duration was negatively correlated with all domains of the WHOQOL-BREF $(\mathrm{p}<0.05)$. The domains except for the environment were negatively correlated with the hospital stay $(\mathrm{p}<0.05)$.

Conclusion: Lower scores of WHOQOL-BREF were achieved in mothers whose children underwent congenital cardiac surgery. Length of intensive care and hospital stay was negatively correlated with the WHOQOL-BREF. Routine screening and counseling may be valuable in this patient population.
\end{abstract}

Keywords: Congenital heart disease, quality of life, surgery.

Congenital heart diseases are major health problems that can affect approximately 0.6 to 1 per 100 live births in the Turkish population. ${ }^{[1]}$ However, there are many different heart diseases in this group, about 50 to $60 \%$ of these patients require surgical treatment. ${ }^{[2]}$ Although pediatric cardiac surgery currently has a highly developed technical and technological infrastructure, operations still have serious morbidity and mortality risks. ${ }^{[3]}$ The parents, particularly mothers, face serious psychosocial problems regarding the risks of the operation and the difficulties of postoperative care. ${ }^{[4]}$ Therefore, the anxiety level of the patients and, particularly, their mothers is critical.

Recognizing the differences in the quality of life (QoL) of the mothers of children undergoing heart surgery compared to mothers of healthy children prepares the ground for screening and supportive treatments in this regard. Determining the psychological and social assessment of these mothers and identifying those who need professional support may explain the source of a social problem. ${ }^{[5]}$ In the present study, we aimed to evaluate the level of QoL of mothers of children undergoing cardiac surgery.

\section{PATIENTS AND METHODS}

This prospective, case-control study was conducted at Dr. Sami Ulus Maternity and Child Health Education and Research Hospital between September $1^{\text {st }}, 2019$ and April 30 $0^{\text {th }}, 2020$. A total of 103 children (52 males, 51 females; mean age:

Corresponding author: Mehmet Taşar, MD. SBÜ Ankara Dr. Sami Ulus Kadın Doğum, Çocuk Sağlığı ve Hastalıkları Ĕgitim ve Araştırma Hastanesi Çocuk Kalp ve Damar Cerrahisi Kliniği, 06080 Altındağ, Ankara, Türkiye.

Tel: +90 312 - 5957159 e-mail: mehmet.tasar@hotmail.com

\section{Citation:}

Taşar S, Taşar M. Assessment of quality of life and psychosocial status of mothers whose children underwent congenital heart surgery. Cardiovasc Surg Int 2021;8(2):86-90. 


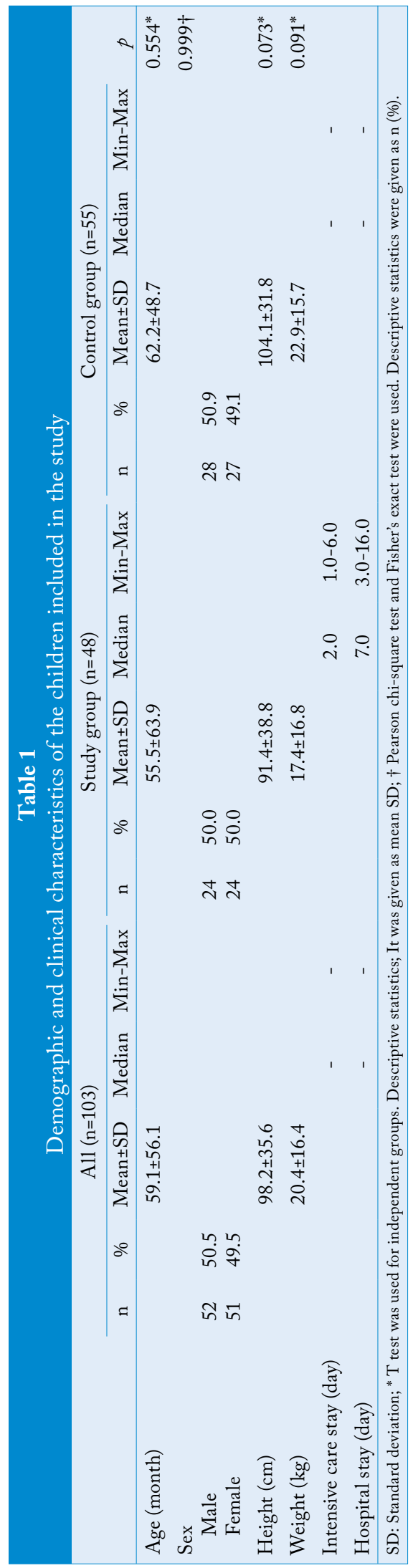

$59.1 \pm 56.1$ months; range, 1 month -18 years) aged between one month and 18 years who underwent congenital heart surgery were included. The children who underwent cardiac surgery and their mothers were included as the study group $(n=48)$. The control group $(n=55)$ included healthy children who were admitted to Ankara Training and Research Hospital during the study period and their mothers. A written informed consent was obtained from each parent. The study protocol was approved by the Ankara Training and Research Hospital, Ethics Committee (date, no: 15.01.2021, E-93471371-514.10). The study was conducted in accordance with the principles of the Declaration of Helsinki.

Socio-demographic data of the children and their mothers were recorded. The World Health Organization Quality of Life-BREF (WHOQOL-BREF) questionnaire was administered to all mothers who participated in the study. The results were compared between the groups. Data including health status, physical health, psychological health, social relations, and environmental status were evaluated.

\section{Statistical analysis}

Statistical analysis was performed using the Microsoft Office Excel, Jamoviproject (2020), Jamovi (version 1.6.1) and JASP (version 0.13.1). Descriptive data were expressed in mean \pm standard deviation (SD), median (min-max) or number and frequency, where applicable. Normality test of numerical variables was checked using the Kolmogorov-Smirnov and Shapiro-Wilk tests. The independent t-test was used to compare two independent groups, while the Mann-Whitney $\mathrm{U}$ test was used when normal distribution

\begin{tabular}{lcc}
\multicolumn{3}{c}{ Table 2} \\
Distribution of diseases in children in the study group \\
Disease & $\mathrm{n}$ & $\%$ \\
Ventricular septal defect & 22 & 45.80 \\
Atrial septal defect & 15 & 31.30 \\
Others & & \\
$\quad$ Aortic coarctation & 11 & 22.9 \\
Tetralogy of Fallot & 4 & 8.30 \\
Totally anomalous pulmonary & 2 & 4.20 \\
$\quad$ venous connection & 2 & 4.20 \\
Single ventricular heart & 1 & 2.10 \\
$\quad$ Valvular disease & 1 & 2.10 \\
Patent ductus arteriosus & 1 & 2.10
\end{tabular}




\begin{tabular}{|c|c|c|c|c|c|c|c|c|c|c|}
\hline & \multicolumn{3}{|c|}{ All (n=103) } & \multicolumn{3}{|c|}{ Study group $(n=48)$} & \multicolumn{3}{|c|}{ Control group $(n=55)$} & \multirow[b]{2}{*}{$p$} \\
\hline & $\mathrm{n}$ & $\%$ & Mean \pm SD & $\mathrm{n}$ & $\%$ & Mean \pm SD & $\mathrm{n}$ & $\%$ & Mean \pm SD & \\
\hline Maternal age (year) & & & $35.0 \pm 7.8$ & & & $34.3 \pm 8.6$ & & & $35.5 \pm 7.1$ & $0.445^{*}$ \\
\hline Education level (\%) & & & & & & & & & & $0.552 \dagger$ \\
\hline None & 8 & 7.8 & & 5 & 10.4 & & 3 & 5.5 & & \\
\hline Primary-secondary school & 57 & 55.3 & & 24 & 50.0 & & 33 & 60.0 & & \\
\hline High school & 32 & 31.1 & & 17 & 35.4 & & 15 & 27.3 & & \\
\hline University & 6 & 5.8 & & 2 & 4.2 & & 4 & 7.3 & & \\
\hline Marital status (\%) & & & & & & & & & & $0.105 \dagger$ \\
\hline Married & 95 & 92.2 & & 47 & 97.9 & & 48 & 87.3 & & \\
\hline Divorced & 7 & 6.8 & & 1 & 2.1 & & 6 & 10.9 & & \\
\hline Widow & 1 & 1.0 & & 0 & 0.0 & & 1 & 1.8 & & \\
\hline Additional disease (\%) & & & & & & & & & & $0.057 \dagger$ \\
\hline Yes & 17 & 16.5 & & 12 & 25.0 & & 5 & 9.1 & & \\
\hline No & 866 & 83.5 & & 36 & 75.0 & & 50 & 90.9 & & \\
\hline
\end{tabular}

assumption was unmet. For multiple comparisons, the Kruskal-Wallis test was used. The Pearson chi-square test was performed to examine the relationship between variables. A $p$ value of $<0.05$ was considered statistically significant.

\section{RESULTS}

There were 48 patients in the study group with a mean age of $55.5 \pm 63.9$ months and 55 healthy children with a mean age of $62.2 \pm 48.7$ months in the control group. There was no significant difference in the age, height, and weight values between the two groups $(\mathrm{p}=0.554, \mathrm{p}=0.073$, and $\mathrm{p}=0.091)$. The median length of intensive care unit (ICU) and hospital stay after surgical treatment was 2 (range, 1 to 6) and 7 (range, 3 to 16) days (Table 1).

In the study group, the most common diagnoses were ventricular septal defect in $22(45.8 \%)$ patients

\begin{tabular}{|c|c|c|c|c|}
\hline \multicolumn{5}{|c|}{$\begin{array}{c}\text { Table } 4 \\
\text { Comparison of WHOQOL-BREF raw score and percentage score between groups }\end{array}$} \\
\hline & All $(n=103)$ & Study group $(n=48)$ & Control group $(n=55)$ & \multirow[b]{2}{*}{$p$} \\
\hline & Mean $\pm S D$ & Mean \pm SD & Mean \pm SD & \\
\hline \multicolumn{5}{|l|}{ Raw score } \\
\hline Health status & $6.3 \pm 1.8$ & $5.7 \pm 2.0$ & $6.8 \pm 1.5$ & 0.004 \\
\hline Physical health & $20.9 \pm 4.6$ & $18.2 \pm 3.6$ & $23.3 \pm 4.1$ & $<0.001$ \\
\hline Psychological health & $19.6 \pm 3.7$ & $18.0 \pm 3.5$ & $21.1 \pm 3.2$ & $<0.001$ \\
\hline Social relations & $9.4 \pm 3.1$ & $8.0 \pm 3.3$ & $10.6 \pm 2.5$ & $<0.001$ \\
\hline Environment & $25.7 \pm 5.6$ & $23.3 \pm 5.0$ & $27.8 \pm 5.4$ & $<0.001$ \\
\hline \multicolumn{5}{|l|}{ Percentage point (\%) } \\
\hline Health status & $53.6 \pm 22.7$ & $46.6 \pm 24.7$ & $59.8 \pm 19.0$ & 0.004 \\
\hline Physical health & $49.6 \pm 16.5$ & $40.0 \pm 13.0$ & $58.1 \pm 14.5$ & $<0.001$ \\
\hline Psychological health & $56.8 \pm 15.2$ & $49.9 \pm 14.5$ & $62.7 \pm 13.3$ & $<0.001$ \\
\hline Social relations & $53.9 \pm 25.5$ & $42.9 \pm 26.5$ & $63.3 \pm 20.5$ & $<0.001$ \\
\hline Environment & $55.3 \pm 17.6$ & $47.9 \pm 15.5$ & $61.8 \pm 16.8$ & $<0.001$ \\
\hline $\begin{array}{l}\text { SD: Stantard deviation; WHC } \\
\text { groups. Descriptive statistics; } \\
(\mathrm{p}<0.05) \text {. }\end{array}$ & $\begin{array}{l}\text { World Health } \\
\text { mean standarc }\end{array}$ & $\begin{array}{l}\text { ation Quality of Life Scale } \\
\text { tion. P values indicated in }\end{array}$ & $\begin{array}{l}\text { hort Form } T \text { test was used fo } \\
\text { old were considered statistica }\end{array}$ & $\begin{array}{l}\text { ndependent } \\
\text { significant }\end{array}$ \\
\hline
\end{tabular}




\begin{tabular}{|c|c|c|c|c|c|c|}
\hline \multicolumn{7}{|c|}{$\begin{array}{c}\text { Table } 5 \\
\text { Correlation of WHOQOL-BREF raw score and percentage scores with age, intensive care and length of } \\
\text { stay in the study group }\end{array}$} \\
\hline & \multicolumn{2}{|c|}{ Age } & \multicolumn{2}{|c|}{ Intensive care stay } & \multicolumn{2}{|c|}{ Hospital stay } \\
\hline & Spearman Rho & $p$ & Spearman Rho & $p$ & Spearman Rho & $p$ \\
\hline Health status & 0.156 & 0.290 & -0.466 & $<0.001$ & -0.304 & 0.035 \\
\hline Physical health & 0.239 & 0.102 & -0.351 & 0.014 & -0.380 & 0.008 \\
\hline Psychological health & 0.089 & 0.547 & -0.530 & $<0.001$ & -0.330 & 0.022 \\
\hline Social relations & 0.134 & 0.364 & -0.339 & 0.019 & -0.385 & 0.007 \\
\hline Environment & 0.062 & 0.675 & -0.315 & 0.029 & -0.279 & 0.055 \\
\hline Health status (\%) & 0.156 & 0.290 & -0.466 & $<0.001$ & -0.304 & 0.035 \\
\hline Physical health (\%) & 0.239 & 0.102 & -0.351 & 0.014 & -0.380 & 0.008 \\
\hline Psychological health (\%) & 0.089 & 0.547 & -0.530 & $<0.001$ & -0.330 & 0.022 \\
\hline Social relations (\%) & 0.124 & 0.408 & -0.317 & 0.030 & -0.362 & 0.012 \\
\hline Environment (\%) & 0.062 & 0.675 & -0.315 & 0.029 & -0.279 & 0.055 \\
\hline
\end{tabular}

and atrial septal defect in 15 (31.3\%) patients. Among the diseases in the other group, aortic coarctation was observed in four (8.3\%) patients (Table 2).

The mean age of the mothers was $35.0 \pm 7.8$ years. Primary-secondary school graduation was the most common (55.3\%) educational status. Maternal age and education status were similar between the groups $(\mathrm{p}=0.445$ and $\mathrm{p}=0.552)$. Ninety-five of the mothers $(92.2 \%)$ were married. The number of mothers with a coexisting disease was 17 (16.5\%). The most common comorbidity requiring drug therapy was hypothyroidism/hyperthyroidism $(n=8)$. Four mothers (3.88\%) used antidepressant drugs and two of them (1.94\%) started using drugs due to poor health status of their children. There was no significant difference between the groups in terms of marital status and having comorbidities $(\mathrm{p}=0.105$ and $\mathrm{p}=0.057)$ (Table 3$)$.

According to the WHOQOL-BREF, the raw score and percentage point percentages of the fields (health status, physical health, psychological health, social relations and environment status) in the study group were significantly lower than the control group ( $<<0.05$ for all) (Table 4).

There were significant negative correlations between the length of stay in the ICU and hospital, and the raw score and percentage scores of all WHOQOLBREF subdomains $(\mathrm{p}<0.05$ for all) (Table 5).

\section{DISCUSSION}

In Turkey, nearly 5,000 to 6,000 children need surgical treatment every year for congenital heart diseases. ${ }^{[1]}$ There are hundreds of very different and complex pathologies in this group. Due to the physiological process of the diseases and the complex nature of surgical applications, the level of anxiety in the mothers of these patients is high at every stage of surgical treatment, which may negatively affect the QoL. ${ }^{[6]}$

Changes in the psychological status and QoL of sick children and their families affect many stages of treatment, but should also be considered as a social problem. Statistical findings and quality scales are used to improve the QoL of the mothers of these children. ${ }^{[7]}$

Cardiac surgery procedures can be fearful for pediatric patients and their families. The individual who needs the most support at this stage is the mother. The mother must be supported psychologically and mentally at every stage of the treatment. The key is that clinicians have emphasized physical and psychological health, social relationships, and environment domains of mothers. Assessment of QoL by using specific tests can be a guide for determining the need for support and therapy. Also, these tests are useful in evaluating the treatment plan and effectiveness. 
In our study, four mothers used antidepressant drugs and only two of them were related to their children' cardiac diseases. However, awareness of mothers about their psychological status is significantly low, leading to poor QoL. Providing professional psychological counseling can be beneficial both in terms of increasing awareness and identifying patients who would be given advanced treatment such as drug therapy or psychiatric support. By increasing the awareness, it may be possible to draw the attention of physicians, nurses, and other health personnel who provide health services to this issue.

However, all QoL scores were significantly lower in the study group, length of stay in the ICU and hospital were related to poor QoL scores. We believe that these mothers deserve to be taken into account specifically.

Quality of life should be improved by recognizing and supporting mothers who are in a difficult process by determining what the changes in QoL are and their severity. ${ }^{\left[{ }^{[]}\right.}$In this way, both the psychological development of sick children and their mothers is supported and social psychological recovery is contributed. For this purpose, in our study, we evaluated the QoL with a questionnaire study among mothers of children with heart disease who underwent surgery.

The data in this study are based on the responses of the voluntary participating mothers to the questionnaires. As the results were subjective, they may have been affected by ethnic changes. The statistical significance between changes could have been increased with a higher number of participants.

In conclusion, the physical health, psychological health, social relations and environmental status of the mothers of children undergoing cardiac surgery seem to be significantly lower compared to healthy mothers.
We believe that it is important to increase the QoL of these mothers with psychological support.

\section{Declaration of conflicting interests}

The authors declared no conflicts of interest with respect to the authorship and/or publication of this article.

\section{Funding}

The authors received no financial support for the research and/or authorship of this article.

\section{REFERENCES}

1. Ündar A, Bakır İ, Haydin S, Erek E, Ödemiş E, Yivli P, et al. Türkiye'de doğumsal kalp hastalıkları cerrahisinin bugünü ve yarını. Turk Gogus Kalp Dama 2012;20:181-5.

2. Mat Bah MN, Sapian MH, Jamil MT, Abdullah N, Alias EY, Zahari N. The birth prevalence, severity, and temporal trends of congenital heart disease in the middle-income country: A population-based study. Congenit Heart Dis 2018;13:1012-27.

3. Martin GR, Jonas RA. Surgery for congenital heart disease: Improvements in outcomes. Am J Perinatol 2018;35:557-60.

4. Kumar A, Das S, Chauhan S, Kiran U, Satapathy S. Perioperative anxiety and stress in children undergoing congenital cardiac surgery and their parents: Effect of brief intervention-a randomized control trial. J Cardiothorac Vasc Anesth 2019;33:1244-50.

5. Simeone S, Platone N, Perrone M, Marras V, Pucciarelli G, Benedetti $M$, et al. The lived experience of parents whose children discharged to home after cardiac surgery for congenital heart disease. Acta Biomed 2018;89:71-7.

6. Sjostrom-Strand A, Terp K. Parents' experiences of having a baby with a congenital heart defect and the child's heart surgery. Compr Child Adolesc Nurs 2019;42:10-23.

7. Woolf-King SE, Anger A, Arnold EA, Weiss SJ, Teitel D. Mental health among parents of children with critical congenital heart defects: A systematic review. J Am Heart Assoc 2017;6:e004862.

8. Denniss DL, Sholler GF, Costa DSJ, Winlaw DS, Kasparian NA. Need for routine screening of health-related quality of life in families of young children with complex congenital heart disease. J Pediatr 2019;205:21-8.e2. 